\title{
Indicators of Adaptive Leadership for Teachers in Boromarajonani College of Nursing Under Boromarachanok Institute: Developing and Testing the Structural Relationship Model
}

\author{
Ratchanee Potchana ${ }^{1}$, Wirot Sanrattana ${ }^{2} \&$ Paisan Suwannoi $^{3}$ \\ ${ }^{1}$ Doctoral student in Educational Administration Program, Mahamakut Buddhist University, Northeastern \\ Campus, Thailand \\ ${ }^{2}$ Thesis adviser in Doctoral Program of Educational Administration, Mahamakut Buddhist University, \\ Northeastern Campus, Thailand \\ ${ }^{3}$ Thesis co-adviser in Doctoral Program of Educational Administration, Mahamakut Buddhist University, \\ Northeastern Campus, Thailand
}

Correspondence: Associate Professor Dr. Wirot Sanrattana, Doctoral Program of Educational Administration Mahamakut Buddhist University, Northeastern Campus, Thailand. E-mail: wirsan@kku.ac.th

Received: March 26, 2020 Accepted: April 30, 2020 Online Published: May 15, 2020

doi:10.5539/jel.v9n3p92 URL: https://doi.org/10.5539/jel.v9n3p92

\begin{abstract}
Background of the study: Leadership is needed when one must deal with education management which means the relationship of influence between the leader and followers who have the same goal, to make a change. It can be used as a guideline in the planning and creating evaluation criteria to improve the adaptive leadership of teachers at Boromarajonani College of Nursing which consistent with the theory and the research result as well as the vision from scholars and organization. Objective: The objectives of this research were to (a) develop a theoretical model of structural relationship of major components, minor components and indicators of adaptive leadership, (b) test the fitness of the model was developed from theoretical model and empirical data, and (c) verify the factor loading value of the major components, minor components and indicators. Materials and Methods: The descriptive research collected by using the 5-level rating scale questionnaire. The population consisted of 1,740 teachers in Boromarajonani college of nursing under Boromarajchanok Institute. The data analysis using AMOS statistical program was done with the 617-return questionnaire. Results: The results showed that the theoretical model was consistent with empirical data with the following statistical metrics: relative Chi-square $(\mathrm{CMIN} / \mathrm{DF})<3.00$, root mean square error of approximation (RMSEA) $<0.05$, goodness-of-fit index (GFI), adjusted goodness-of-fit index (AGFI), comparative fit index (CFI), and normed fit index (NFI) $0.90-1.00$ were in accordance with the criteria from both the first and second order of confirmative factor analysis. The major components had factor loading ranging from 0.71 to 1.00 , which is higher than the criterion as 0.70 . The minor components and indicators had factor loading are higher than the criterion as 0.30 . Conclusion: The finding can be used as a guideline in the planning and creation of evaluation criteria to improve the adaptive leadership of teachers at Boromarajonani College of Nursing which is consistent with the theory and research results as well as the vision from scholars and organization. This will help improve the performance efficiency of the teachers at Boromarajonani College of Nursing which will affect the education management and education improvement.
\end{abstract}

Keywords: indicator, Adaptive leadership, teacher in Boromarajonani college of nursing

\section{Introduction}

\subsection{Introduce the Problem}

A leader is the main factor in successful work and organization. Leadership is needed when one must deal with education management which means the relationship of influence between the leader and followers who have the same goal to make a change (Khottakarn, 2019). Nowadays, the leader who gives out tasks is not needed but the one who sets the main purpose between the leader and followers which can draw people toward success. This skill is essential to manage education in this era, especially the leader who have adaptive leadership skill that can face any inconstancy challenges. These problems can be handled by the person who has adaptability, priority, 
faith, vision risk taker and adaptive challenge. The inconstancy problem needs the leader who can adapt to any situation more than the leader who gives out orders according to the organization's structure (Heifetz, Grashow, \& Linsky, 2018).

Director and teachers in education place need to show their leadership because the person who takes the role to manage the education for the student to become according to the curriculum and the change of nowadays world need to have adaptive leadership. Due to education is the adaptive change, it does not have the instant answer that will guide or regulate from the external. Instead, one needs to find a solution by changing one's attitude, value and behavior. To have a long-term solution of the problem, the leader needs to take a risk to switch one's role and the power that one obtains to push for changes as well as handle the changes and can compete in the international level. To handle the changes, the leader needs to have a vision and direction. The leader must be able to communicate one's vision to comply with the people in the organization and motivate people to complete the goal together (Gillespie, 2017). At the same time, the challenge of $21^{\text {st }}$ century education is how to prepare the student for life in vary society of this era. The teacher needed to be alert and be prepared to manage the curriculum especially the learning skill (Phanich, 2013). It is essential to improve the teacher abilities to be the $21^{\text {st }}$ century teacher, to adapt the concept of teach, to promote the learning, to adjust the classroom and to support the learning process.

Adaptive leadership is a suitable concept for the director and teacher in this era (Gillespie, 2017). According to previous studies, there are several components of adaptive leadership. For example, there are 4 characteristics of an adaptive leaser: 1) vision and purpose of organization, 2) the utilization of people skills and experience in assisting with adaptation, 3) able to tolerate ambiguity, and 4) freedom to act (Heifetz, Grashow, \& Linsky, 2018; Gillespie, 2017; Phanich, 2013; Geyer, 2005; Grensing-Pophal, 2013; Mowbray, 2014; Chaichana, 2014). The lack of unity among these studies makes it difficult to use the knowledge presented in improving staff and improving the suitable research process. The researcher sees that to enchant and experiment on the structural model to indicate the dative leader with the research important. It can help create new knowledge that passes the theory synthesis process and the result of the research as well as other opinions. This can be uses to improve the staff in a systematic way and the suitable research especially the improvement of teachers at Boromarajonani College of Nursing to be according to the higher education standard and the professional standard in this vary era Therefore, this study aimed to improve and to test the structural relationship model that indicates the state of adaptive leadership for the teachers at Boromarajonani College of Nursing by using the empirical definition were researcher indicate the sub-variable and summation of sub-variable by using the theory and basic research. This will limit the weight of the sub-variable by using the empirical data analysis (Wiratchai, 2002). We studied the theory and many researches as well as the vision of the scholars and the organization from different sources to composite the main elements, sub-elements, operational definition and the indicators. This led to the establishment of the structural relationship that the researcher can test the consistency of the model that evolved from the theory and the research result, coup with the vision from scholars and empirical information of the organization. If found that this model created by the researcher is consistent to the empirical information according to the specific standard, it means that this new knowledge is suitable for Thai society and can be used as the reference for the continual research and use to perfection in the future. Moreover, it can be used as a guideline in the planning and create the evaluation criteria to improve the adaptive leadership of the teachers at Boromarajonani College of Nursing which consistent with the theory and the research result as well as the vision from scholars and organization. This will help improve the performance efficiency of the teachers at Boromarajonani College of Nursing which will affect the education management and education improvement.

In this research, we studied the main element of adaptive leadership from theories and research result from 15 sources and found out that there are 24 elements of the main theoretical framework. After the selection of the highest frequency of leadership attributes (6 and above) found that there are 4 main compositions of Adaptive Leadership (ADA) that can be used in this research. There are Managing Skills (MAN), Visionary (VIS), A Freedom of Act (FRE) and Adaptive Challenge (ADA). We studied the sub-elements of each main components and found that (a) Managing Skills (MAN) has 5 sub-elements which are Organization (MAN1), Communication (MAN2), Planning (MAN3), Conflict management (MAN4) and Change management (MAN5), (b) Visionary (VIS) has 3 sub-elements which are Risk-taking (VIS1), Innovator (VIS2) and Imaginative (VIS3), (c) A Freedom of Act (FRE) consist of 4 sub-elements, Delegation (FRE1), Encourage creativity (FRE2), Provide support (FRE3) and Trust (FRE4), (d) Adaptive Challenge (ADA) has 4 sub-elements which are Seek new way (ADA1), Foster adaptation (ADA2), Focus on Success (ADA3) and Develop adaptability (ADA4). From the following result, it creates the theoretical model of adaptive leadership that can be used in the research to show the structural relationship model that consisted of 4 main components and 16 sub-elements. 


\subsection{Research Questions}

The proposed model was examined for its consistency with the empirical data collected from the selected samples of the population of Boromarajonani college of nursing under Boromarajchanok Institute of Thailand.

\subsection{Research Hypothesis}

The structural relationship model of Adaptive Leadership that shows the structural relationship between 4 main elements, 16 sub-elements and 83 indicators that we developed from the theoretical frameworks, previous studies and various primary data to identify the key components and sub-components of the model (Wiratchai, 2002). There is a study of theory and research result from different sources and the conclude the result by using the synthesis method to get the main components, sub-elements and indicators that fit the construct validity and content validity. Moreover, from the study of the Adaptive Leadership Indicators for Basic Education research stated that has the aim to test the theoretical model and the construction of theoretical model by using empirical definition (Chaichana, 2014). We discover that the research result is going according to the research hypothesis, therefore in this study, we had set the research hypothesis to estimate the answers as followed: (a) The theoretical model of Adaptive Leadership which has been created to consistent with the empirical data by determined the standard examination from (Hair, Black, Babin, \& Anderson, 2010) which are (1) Relative Chi-Square (CMIN/DF) is less than 3.00. (2) Root Mean Square Error of Approximation (RMSEA) is lower than 0.05 (3) Goodness-of-Fit Index (GFI) (4) Adjusted Goodness-of-Fit Index (AGFI) (5) Comparative Fit Index (EFI) and (6) Normed Fit Index (NFI) is rated from 0.90-1.00, (b) The main component in the theoretical model of Adaptive Leadership weights loading facto equal or higher than 0.70 (Farrell \& Rudd, 2009). The sub-elements and indicators weight loading factor equal to or higher than 0.90 (Tacq, 1997). According to the model, we examined the operational definition of each sub-elements to identify the linkage between the indicators that reflected the leadership behaviors of each sub-elements. A total of 83 indicators were composed of a structural relationship model of Adaptive Leadership both in the key component and sub-component levels.

\section{Method}

\subsection{Participants}

In this descriptive research design, the population included 1,740 teachers at Boromarajonani College of Nursing from 30 different branches across Thailand. They are the sample group by using the ratio rule between the sample unit per parameter 20:1. From collecting the parameter of latent variables, there are 5 variables, 17 observed variables and 21 influence line which in total there are 43 parameters that make the research sample group of 860 participants.

\subsection{Methods}

There were three processes to improve the education indicators including (a) the pragmatic definition is the process that the researcher used one's own experience to select the variables in the model, (b) the theoretical definition was the process the researcher uses theory and model's research result and could present the model or have the supervisor to examine the model before apply, and (c) the empirical definition was the process that researcher use theory and model's research result and to test that model with empirical data. If we found that there was a match with the thermotical model, the empirical data will be collected from the random study group. Also, analyzing the data by the confirmative factor analysis were used (Wiratchai, 2002). In this study, we used the empirical definition to improve the indicators which showed more scientific process from using the empirical data that collected from the random study group to make the correct judgment (Sanrattana, 2018). Therefore, there will be no weakness or bias from the feeling or personal experience of the researcher or the supervisors.

\subsection{Instruments}

The questionnaires were divided into two parts including (1) questionnaire about the status of the target in the checklist format, and (2) questionnaire about the behavior and reaction toward adaptive leadership of the teachers at Boromarajonani College of Nursing which had 5 rating scal. To differentiate the subject matter of the main component and sub-elements, there were 83 questions that we had composed by ourselves from the working process including (a) to study the theory and research result to synthesize and indicate the main components, (b) to examine theory and research result to synthesize and indicate each sub-element of the main components, (c) to study theory and research result to synthesize and indicate each indicator of the sub-elements, (d) to create the questionnaires from the indicators and create the examination form that consistency with the indicators and let 5 experts from education management field examine the consistency of the question and the indicators, and (e) to improve the questionnaires that we got from try-out with ransom sample group of 30 teachers at Boromarajonani College of Nursing who were not the study group in the research. Also, to use this 
data to analyze the alpha coefficient of reliability by process of Cronbach. The result of the data analysis showed that the questionnaire had the alpha coefficient of reliability of 0.98 . When segregate each main component, we found that Managing skill was equal to 0.95 . Visionary was equal to 0.94, A Freedom of Act was equal to 0.96 and Adaptive Challenge was equal to 0.95 which showed that this alpha coefficient of reliability was higher than the standard of 0.70 (Prasertratasin, 2003).

\subsection{Data Collection}

The population included 1,740 teachers at Boromarajonani College of Nursing across the country as mentioned above. We used multi-stage random sampling process by using the nursing college as the proportional random sampling. According to the proportion of the study group, we got 860 people as the study group to collect the data. After that, we sent the questionnaire to the study group via mail. After followed up with them for five months, we got the answer back from 617 participants. It was 71.75 percent of the whole study group. From the number of responses that we received back, we examined them with the Kaiser-Meyer Olkin (KMO) test for sampling adequacy found that the result is between 0.935-0.956. This meaned the questionnaire for the ransom sample group of 617 participants was enough to analyze the confirmatory factors.

\subsection{Data Analysis}

All data were analized by using a statistical program to find (a) frequency and percentage showing fundeamental information of sample group, (b) mean and coefficient of distribution measuring all suitable indicators, (c) correlation coefficient of Pearson and Bartlett to examine the suitability of variables that used for analyzing the confirmatory factors, (d) Kaiser-Meyer-Olkin (KMO) test for sampling adequately, (e) to examine the adequacy of the questionnaire toward the analysis of the confirmatory factors, and (f) the first order of Confirmatory Factor Analysis and the second order of Confirmatory Factor Analysis to test the consistency of the theoretical model and the empirical model by using the AMOS program, respectively.

\section{Results}

The result of the first order of Confirmatory Factor Analysis was to test the consistency of the model by using four main components which were measurement model of managing skills, measurement model of visionary, measurement model of a freedom to act, and measurement model of adaptive challenge. We found that each component indicated model was fitted with empirical data as indicated in Table 1.

Table 1. First order of confirmatory factor analysis to test the consistency of four theoretical models with the empirical data

\begin{tabular}{|c|c|c|c|c|c|c|}
\hline Measurement Model/Criteria & $\begin{array}{l}\text { CMIN } \\
<3.00 \\
\end{array}$ & $\begin{array}{l}\text { RMSEA } \\
<0.05\end{array}$ & $\begin{array}{l}\text { GFI } \\
0.90-1.00\end{array}$ & $\begin{array}{l}\text { AGFI } \\
0.90-1.00\end{array}$ & $\begin{array}{l}\text { CFI } \\
0.90-1.00\end{array}$ & $\begin{array}{l}\text { NFI } \\
0.90-1.00\end{array}$ \\
\hline $\begin{array}{l}\text { Managing skills (MAN) } \\
\text { - Organization (MAN1) } \\
\text { - Communication (MAN2) } \\
\text { - Planning (MAN3) } \\
\text { - Conflict Management (MAN4) } \\
\text { - Change Management (MAN4) }\end{array}$ & 2.297 & 0.046 & 0.938 & 0.903 & 0.974 & 0.955 \\
\hline $\begin{array}{l}\text { Visionary (VIS) } \\
\text { - Risk Taking (VIS1) } \\
\text { - Innovator (VIS2) } \\
\text { - Imaginative (VIS3) }\end{array}$ & 2.513 & 0.050 & 0.979 & 0.942 & 0.992 & 0.987 \\
\hline $\begin{array}{l}\text { A Freedom to Act (FRE) } \\
\text { - Delegation (FRE1) } \\
\text { - Encourage Creativity (FRE2) } \\
\text { - Provide Support (FRE3) } \\
\text { - Trust (FRE4) }\end{array}$ & 2.505 & 0.049 & 0.951 & 0.918 & 0.918 & 0.970 \\
\hline $\begin{array}{l}\text { Adaptive Challenge (ADA) } \\
\text { - Seek New Way (ADA1) } \\
\text { - Foster Adaptation (ADA2) } \\
\text { - Focus on Success (ADA3) } \\
\text { - Develop Adaptability (ADA4) }\end{array}$ & 2.481 & 0.049 & 0.947 & 0.911 & 0.982 & 0.970 \\
\hline
\end{tabular}

The result of this study confirmed that Managing skills (MAN), Visionary (VIS), A Freedom to Act (FRE) and Adaptive Challenge (ADA) were four main components of Adaptive Leader (ADAP) as shown in Table 2. 
Table 2. The Managing skills (MAN), Visionary (VIS), A Freedom to Act (FRE) and Adaptive Challenge (ADA) is the main component of Adaptive Leader (ADAP)

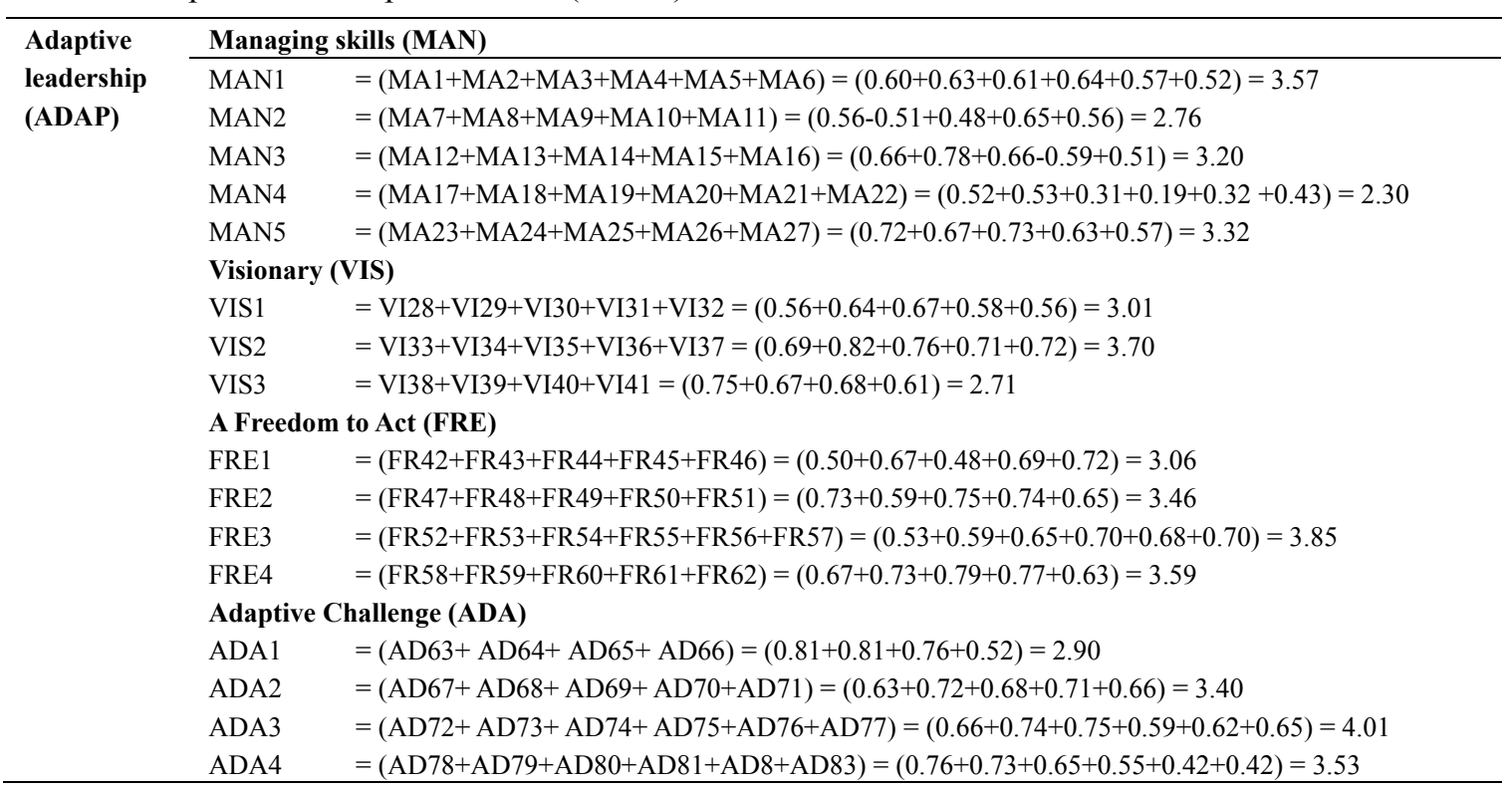

From the above sub-component scales, we revealed the measurement model of Adaptive Leadership to analyses data consistent with the model and empirical data by analyzing the second order of Confirmatory Factor Analysis. The result showed that the measurement model of Adaptive Leadership which was the theoretical model consistent with the empirical data by examining from the comparison statistic as shown in Table 3.

Table 3. Second order of confirmatory factor analysis to be tested the consistency of the theoretical model of Adaptive leadership (ADAP) and empirical data

\begin{tabular}{lllllll}
\hline Measurement Model/Criteria & CMIN & RMSEA & GFI & AGFI & CFI & NFI \\
& $<3.00$ & $<0.05$ & $0.90-1.00$ & $0.90-1.00$ & $0.90-1.00$ & $0.90-1.00$ \\
\hline Adaptive leadership (ADAP) & 1.315 & 0.023 & 0.988 & 0.965 & 0.998 & 0.994 \\
- Managing skills (MAN) & & & & & & \\
- Visionary (VIS) & & & & & & \\
- A Freedom to Act (FRE) & & & & & \\
- Adaptive Challenge (ADA) & & & & & \\
\hline
\end{tabular}

Moreover, we have verified the loading factors of these four main components and found that the positive outcome and important statistical significance were in the level of .01 for every factor. Each of four main components had the following loading factors: (1) Managing skills (MAN) $=1.00$ (2) Visionary (VIS) $=0.86(3)$ A Freedom to Act $(\mathrm{FRE})=0.81$ and (4) Adaptive Challenge $(\mathrm{ADA})=0.71$ for making component scale of adaptive leadership (ADAP) leading to ADAP $=1.00(\mathrm{MAN})+0.86(\mathrm{VIS})+0.81(\mathrm{FRE})+0.71(\mathrm{ADA})$, respectively. This study also found that (a) the loading factors of all four main components had the positive outcome and statistical significance in the level of .01 for every factor. The component of Adaptive Challenge (ADA) had the lowest factor loading which was 0.71 and was higher than the indicated standard, at the level of 0.70 , (b) the loading factor of 16 sub-elements was positive and statistical significance in the level of .01 for every factor. Communication of sub-elements had the lowest factor loading which was 0.72 and was higher than the indicated standard, which was in the level of 0.30 , and (c) the loading factor of 83 indicators was positive and statistical significance in the level of .01 for every factor. Avoiding conflict (MA20) had the lowest factor loading which was 0.59 and was higher than the indicated standard which was in the level of 0.30 . All number of every components in different levels showed that the theoretical model of Adaptive Leadership (ADAP) displayed the structural relationship of all four main components, 16 sub-elements and 83 indicators, respectively. Consequencly, the present result could be used as the guideline to improve the teachers in Boromarajonani college of nursing under Boromarajchanok institute in the construct validity way. 


\section{Discussion}

The present result and previous theories stayed in the line with hypothesis and vision of the scholars and organization which were used in this study as in an international level. Furthermore, previous theories and the present result as well as vision were consistent with the adaptive leadership behavior of teachers at Boromarajonani College of Nursing in Thai society. Arised from the advance in technology that helps with the communication could helps to distribute international theories and the present result as well as vision about the adaptive leadership to Thai society and education. This has an impact on people, who are consistent with the theory of the present research result in order to shift their behaviors toward the adaptive leadership behavior. All these visions stated that it is the procedure that combined the world population into one society (Kerlinger \& Lee, 2000). Globalization happened by joining force between the economic, technology, culture and politics, it might be happended as Thai education starts to realize more about the change of adaptive leadership in this $21^{\text {st }}$ century which is also happening around the world. This causes the change in behavior that shows in adaptive leadership according to the world's trend. The leader in this current era where things change quickly needed to win toward the impediment first (Kerlinger \& Lee, 2000). Thus, one could lead the organization to the success. The leader in changing era needs to have proper qualification and behavior to reduce the tension and facilitate the working environment (Grensing-Pophal, 2013). On the other hand, teachers at Boromarajonani College of Nursing in Thai society can show their adaptive leadership that consistent with the theories and the present result as well as vision toward the adaptive leadership from international level by trying to improve to the $21^{\text {st }}$ century. The era that everything changes in quick causes education plan also adapt to it. Especially, the leader or teacher need to adapt their vision to not fix in the form. The director and teachers need to have the ability to adapt toward the change and turn the crisis into opportunity to make the organization grow in any kind of situation. We also found that factor loading weight of the main components, sub-components and indicators of the theoretical model of adaptive leadership had values as the indicated standard. They are the weight of the main component was equal or higher than 0.70 and the weight of the sub-element as well as indicators were equal or higher than 0.30 . The main reason is from the main components, sub-elements and indicators that used in this study. We had studied previous theories and related studies from different sources, then analyzed and put them into the model concerning about the validity of the content or the variable in every process. In the indication process, all main component, sub-elements and the operational definition were indicated in the indication. It showed that the theoretical model of Adaptive Leadership and the present result could be used to improve the adaptive leadership of the nurse teachers in which all contenta and the activities covering all main components such as management skill, vision, freedom to operate and adaptive challenge, respectively. The main research components that use in this study came from 15 different sources. They included 24 elements that fitted to the main component of the theories but the one that got selected to use in the study had the high frequency of four main components. This caused other twenty components disqualified from the present study. Some of the components might come from the new important result such as leadership, tolerate ambiguity, development, sense and respond, as well as flexibility, respectively

\section{Conclusion}

This study found that the theoretical model of adaptive leadership was consistence with the indicated empirical data. Further study on adaptive leadership indicator coupled with other organization could improve on adaptive leadership of teacher in nursing college and include all components to improvement it. The present study can be used as a guideline in the planning and creation of evaluation criteria to improve the adaptive leadership of teachers at Boromarajonani College of Nursing which is consistent with the theory and research results as well as the vision from scholars and organization. This will help improve the performance efficiency of the teachers at Boromarajonani College of Nursing which will affect the education management and education improvement.

\section{References}

Chaichana, S. (2014). Indicator of Leadership for Educational Administrative Officer. Khon Khaen University, Khon Khaen.

Farrell, A. M., \& Rudd, J. M. (2009). Factor analysis and discriminant validity: A Brief review of some practical issues. In D. Tojib (Ed.), ANZMAC 2009 conference proceedings. ANZMA.

Geyer, V. (2005). The authorizer and charter school closures: Exercising adaptive leadership to protect the public interest. Authorizer Issue Brief, 8, 1-5.

Gillespie, N. M. (2017). Teacher leadership as Adaptive Leadership. Retrieved April 6, 2018, from http://www.huffingtonpost.com/nicole-gillespie/teacher-leadership-as-ada_1_b_5679343.html 
Grensing-Pophal, L. (2013). The value of adaptive leadership. Retrieved January 16, 2016 from http://www.hreonline.com/HRE/view/story.jhtml?id=533347270

Hair, J. F., Black, W. C., Babin, B. J., \& Anderson, R. E. (2010). Multivariate data analysis (7th ed.). Upper Saddle River, NJ: Prentice Hall.

Heifetz, R., Grashow, A., \& Linsky, M. (2018). The practice of adaptive leadership. Retrieved February 27, 2016, from http://www.widener.edu/about/widener_values/leadership/oskin_leadership/az/adaptive.aspx

Kerlinger, F. N., \& Lee, H. B. (2000). Foundations of Behavioral Research (4th ed.). Holt, NY: Harcourt College Publishers.

Khottakarn, P. (2019). Leader and Leadership for Organization. Retrieved April 10, 2017, from http://phinit0112.blogspot.com/

Mowbray, D. (2014). Adaptive leadership. Retrieved January 16, 2016, from http://www.mas.org.uk/management-advisory-service/what-makes-a-good-leader/adaptive-leadership-3.htm 1

Phanich, V. (2013). Learning Development to 21 centuries. Bangkok: Kammachon Publishing.

Prasertratasin, S. (2003). Research Methodology in Social Science. Bangkok: Pueng Fah Printing.

Sanrattana, W. (2018). Research in Educational Administration: Concepts, Guidelines, and Case Studies (4th ed.). Bangkok: Tipwisut.

Tacq, J. (1997). Multivariate analysis techniques in social science research: From problem to analysis. London: SAGE Publications.

Wiratchai, N. (2002). Development of Indicators for Assessment of Administration and Management of Educational Service Areas. Bangkok: Thanaksorn.

\section{Copyrights}

Copyright for this article is retained by the author, with first publication rights granted to the journal.

This is an open-access article distributed under the terms and conditions of the Creative Commons Attribution license (http://creativecommons.org/licenses/by/4.0/). 